\title{
Globalization of the Korean Journal of Medical Education
}

Ki-Young Lim

President, The Korean Society of Medical Education

The Korean Society of Medical Education was founded in May 1983 with the aim of supporting the academic study of medical education, introducing and disseminating the latest educational theories and techniques, and supporting the development of teaching competencies. However, over the first 6 years, the society's activities were frequently interrupted, preventing it from playing a role. In 1989 though, the society was reconstructed and started functioning again: the first medical education conference was held in March and the official journal of the society, the Korean Journal of Medical Education (KJME), was published in June.

Over the past 28 years, the Korean Society of Medical Education has made enormous progress, both quantitatively and qualitatively. The conference, which dozens of members attended in the early years, has grown into a large-scale event, with nearly 500 medical educators enthusiastically participating and a higher number and quality of presentations being provided.

The Korean Journal of Medical Education has also become an international English-language journal, published four times a year and listed in MEDLINE and PubMed Central, with ongoing efforts for inclusion in the Science Citation Index (SCI). This is a tremendous development by those dedicated to advancing the Korean Journal of Medical Education.

The journal has now undergone a significant change: Dr. Sun Kim, who has been the editor-in-chief for the last 10 years, has handed over her role to Dr. Young-Mee Lee, and there have been other changes to the editorial board. I am convinced that the journal will develop further under the leadership of both the new editor-in chief and excellent members of the editorial board.

Dear members,

I believe that medical educators should contribute to the development of medical education through their academic activities: conducting research and writing dissertations. Therefore, please support us in enhancing our journal by submitting your highly valuable and authoritative dissertations on medical education. Further, until the journal is included in SCI, any feedback that can improve our academic conferences and journal would be greatly appreciated.

Best wishes.
Received: February 8, 2016 • Revised: February 17, 2016 • Accepted: February 17, 2016 Corresponding Author: Ki-Young Lim (http://orcid.org/0000-0003-0256-4240) Department of Psychiatry and Behavioural Sciences, Ajou University School of Medicine, 164 Worldcup-ro, Yeongtong-gu, Suwon 443-380, Korea Tel: +82-31-219-5180 Fax: +82-31-219-5179 email: kylim@ajou.ac.kr
Korean J Med Educ 2017 Mar; 29(1): 1

https://doi.org/10.3946/kjme.2017.46 eISSN: 2005-7288

(C) The Korean Society of Medical Education. All rights reserved. This is an open-access article distributed under the terms of the Creative Commons Attribution Non-Commercial License (http:// creativecommons.org/licenses/by-nc/3.0/), which permits unrestricted non-commercial use, distribution, and reproduction in any medium, provided the original work is properly cited. 